\title{
A Comparative Study on the Teaching Effects of TRIZ Courses for the Humanities
}

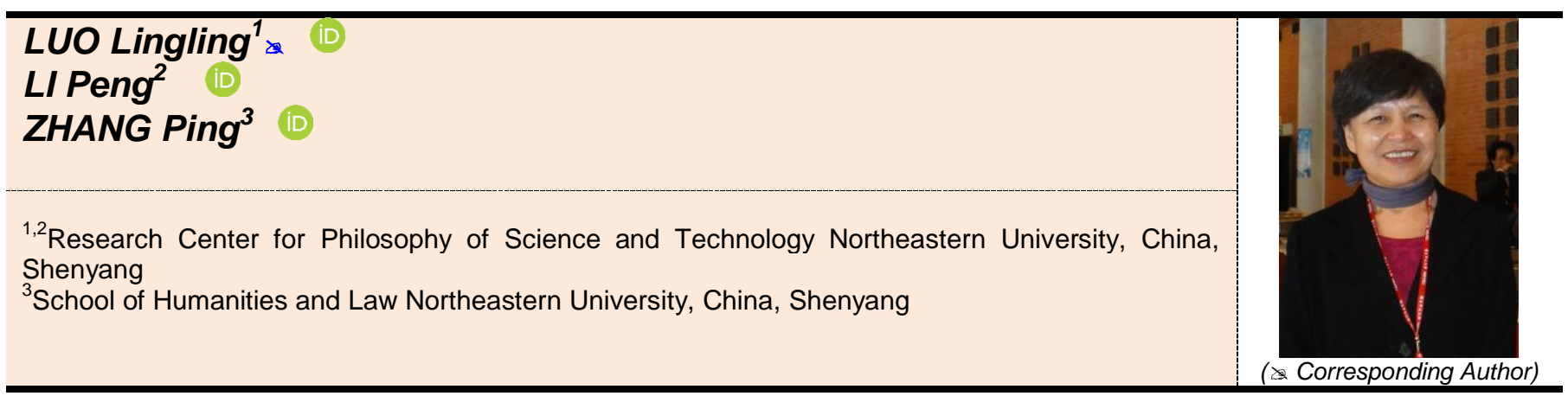

Abstract

In order to test the feasibility of the curriculum system of TRIZ used in humanities and social science majors, this study will test whether it is effective to cultivate students' creativity and to train their ability to solve problems. This study designs the randomly experimental targets in the two control groups for pretest and post-test. This study tests creative thinking and student self-evaluation questionnaire by use of the China Taiwan scholar, Wu Jingji's design. The result indicates that the post-test, for the two groups of students, their creative thinking indicators have improved significantly. The results showed that TRIZ had a significant effect on improving students' creativity. Finally, this study has discussed the value of TRIZ Course contained in Humanities and Social Science Teaching and addressed the needs to improve.

Keywords: TRIZ, TRIZ courses, Creative development course, Creative, Effect, Comparative study.

\section{Contents}

1. The Theoretical Background of this Study

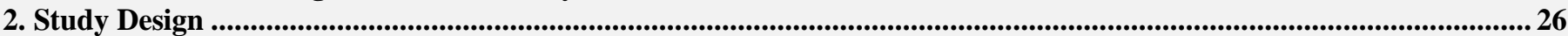

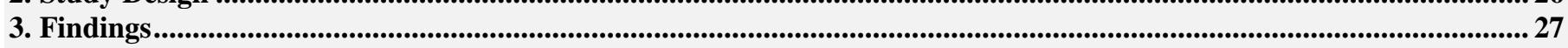

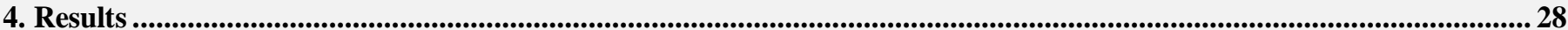

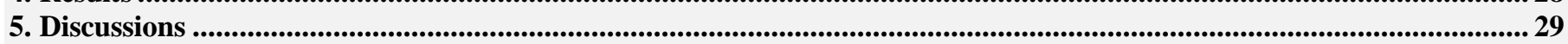

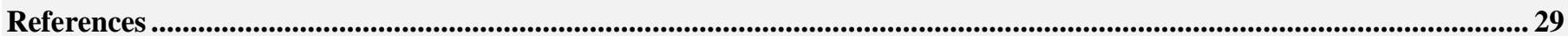

Citation | LUO Lingling; LI Peng; ZHANG Ping (2017). A Comparative Study on the Teaching Effects of TRIZ Courses for the Humanities. Asian Journal of Education and Training, 3(1): 25-29.$$
\text { DOI: }
$$

ISSN(E) :

10.20448 /journal.522/2017.3.1/522.1.25.29 Crossref

$2519-5387$

Contribution/Acknowledgement: All authors contributed to the conception and design of the study.

Funding:

Competing Interests: The authors declare that they have no conflict of interests.

This study received no specific financial support.

History:
Ethical:

Publisher:

The authors confirm that the manuscript is an honest, accurate, and transparent account of the study was reported; that no vital features of the study have been omitted; and that any discrepancies from the study as planned have been explained.

Received: 18 November 2016/ Revised: 9 January 2017/ Accepted: 20 January 2017/ Published: 2 February 2017

This study follows all ethical practices during writing.

Asian Online Journal Publishing Group 


\section{The Theoretical Background of this Study}

\subsection{The Feasibility for TRIZ Innovation Theory Used in Non-Technical Areas}

The earliest works of this field come from the scholars ,Boris Zlotin and Alla Zusman, who explore the possibility of TRIZ innovation theory in the social sciences (Boris and Alla, 1993). And later, some researchers began to explore the possibility of TRIZ innovation theory applied to non-technical areas. because TRIZ analytical tools and psychological operators can be applied directly or can be easily changed to be applied to non-technical areas; for instance, separation and self-service can be seen as parts of the principle of universal (Boris et al., 2000).

Regarding the TRIZ innovation theory applied to specific applied research in non-technical areas, Darrell Mann has led the research team that have made the mostly contributions. On the basis of more than 3 million copies for worldwide successful business management cases, they propose that the TRIZ innovative measures and contradictory parameter matrix can be applicable to business management areas. They argue that the contradictions parameters can be defined from the basic problems arising from business management (Darrell, 2002). Gennady Retseptor presented 40 innovative measures in the field of quality management (Retseptor, 2003) and increased customer satisfaction for the 40 innovative measures (Retseptor, 2007). Jun Zhang, Kah-Hin Chai, Kay-Chuan Tan and others give 40 principles of areas of service operations and they have been equipped with the cases for a corresponding service operation field (Zhang et al., 2003). Dana G.Marsh et.al who give the corresponding cases and 40 innovative measures in the field of education (Marsh, 2004). Yonghai and Jianhua (2009) demonstrated in the study of how to use the principle of separation of four methods - the time separation, spatial separation, separation conditions, separation systems-for business model innovation (Yonghai and Jianhua, 2009). Lv et al. (2010) address the application of innovative measures and contradictory arguments on China's express delivery company's innovation strategy (Lv et al., 2010). Zhang Yaqiang, Sang Xiufeng et al have defined 35 parameters generally from the management areas, and proposed the principle of separation of management field (Zhang and Sang, 2011).

Iran's scholar, Dr.Mohammad H.Saliminamin, based on summarizing the previous migration studies of innovative measures of TRIZ, argues that TRIZ innovative measures virtually are contained in some philosophical elements. These elements are the unit of practical effects in principle and are universal (Saliminamin and Nezafati, 2003). The Chinese scholar, Zhang Dengbo, who pointed out that due to maladaptation to the structural problems, they lead to the TRIZ innovation theory in the field of engineering and technology which can not be directly applied to the non-technical areas. They should abstract TRIZ innovative measures from philosophical and methodological perspectives, interpreted it as a social sphere for innovation measures and test these principles by use of cases (Zhang et al., 2008).

\subsection{Cultivating How to Access the Creativity Teaching}

As early as 2004, it was suggested that the difference between creative teaching and teaching creativity should be clear. The former refers to the use of imaginative approaches to make learning more funny and effective, while the latter concerns about the attitudes of creative teaching, and teaches how to develop students' creative thinking and behavior. Despite the creative teaching has its undeniable value and it is believed that it has a lasting impact, education ultimately should focus on creativity training (Magdalena et al., 2013).

According to Csikszentmihalyi's creativity systems theory (1999), the teacher is the gatekeeper of students' creativity and creative product, whose teaching attitudes and academic expectations of students are under the direct control of the creative results (Csikszentmihalyi, 1988).

Creative potential is usually defined as divergent thinking ability, but as novelty and feasibility. Indicators of divergent thinking is used to examine the improvement of students' creativity as an important way.

\section{Study Design}

\subsection{The Purpose of the Experiment}

The purpose of the experiment is to understand how to implement the TRIZ innovative methods in humanities and social sciences. summarizing directions and recommendations to improve such teaching.

This study chooses the students' innovative teaching contents and manners in humanities and social science as the target and designs teaching TRIZ innovative methods. The different effects of two teaching TRIZ system for training students' creativity are compared.

\subsection{Assessment Tools}

Wu Jingji's creative thinking test scale. The Scale is divided into two parts: a new version of Chinese language for Creativity Thinking Test-unusual uses for bamboo chopsticks, a new version of graphics for Creativity Thinking Test-human shape drawing. Wu Jingji is a well-known scholar of creativity research in China Taiwan, who is the student of E.P. Torrance as the pioneer of creative thinking test (TTCT). He has inherited TTCT measuring mode, but made TTCT test simplify. They use the chopsticks and Chinese words in Chinese culture as the stimuli factor for test, which is more suitable for Chinese participants. The reliability and validity of Wu Jingji's Creative Thinking Test Scale have reached a higher level. The factors for this Scale include fluency, flexibility, originality and elaboration. This kind of divergent thinking test is mainly used to measure divergent thinking creative potential, which is the most mature one for the creativity measurement.

\subsection{Experimental Design Types}

Randomly Assigned to Subjects of Two Controlled Group Measured Before and After the Experiment

\subsection{Experimental Hypothesis}

The experimental studies' assumptions include the following three groups: 
Assumption 1: There are no significant differences between post-test score for the ones who have accepted the primary TRIZ training in liberal arts major in their creative thinking (verbal / graphic) and the ones who have accepted the creative training on a general scale and higher than pretest score.

Assumption 2: The post-test scores of the ones who have accepted the primary TRIZ training in liberal arts major in their creative thinking (verbal / graphic) will be higher than the scores of the ones who accepted the creative training on a general scale.

\subsection{Research Procedures}

(1) Use the creative thinking test (verbal/graphic) to do the experimental pretest for the college students' creative thinking levels in the experimental group and the control group.

(2) For the formal experiment, the control group received 40 hours for learning the general creativity developing courses and the experimental group received 40 hours for TRIZ initial training.

(3) After 10 weeks, at the end of the experiment, the creative thinking test (verbal/graphic) is used again to do the experimental post-test for the college students' creative thinking levels in the experimental group and the control group.

(4) Statistical data processing.

\section{Findings}

In this experiment, the students in the experimental group are from the Major of Administration Management, Public Utilities Management Business, Ideological and Political Education. The teaching content is about TRIZ.

In order not to affect the normal school teaching order, this experiment takes the teaching classes as a unit, and teaching assignment is carried out in accordance with the normal teaching schedule. The experiment has been done from the second semester of the academic year, namely, from 2014 to 2015, through 1 week to 10 weeks (10 weeks with 40 hours).

The experimental group (using TRIZ teaching) and control group (using the traditional teaching of creation) are compared. Test is divided into the following groups:

In the experimental group, verbal test of creative thinking for TRIZ Teaching (i.e. Chopsticks test), and it is short for Experience group chopsticks test. The number of effective sample is 63 .

In the experimental group, graphic test of creative thinking for TRIZ Teaching (i.e. Human shape test), and it is short for Experience group human shape test. The number of effective sample is 81 .

In the control group, verbal test of creative thinking for traditional Teaching (i.e. Chopsticks test), and it is short for Group 2 Chopsticks test. The number of effective sample is 68.

In the control group, graphic test of creative thinking for traditional Teaching (i.e. Human shape test ), and it is short for Group 2 human shape test. The number of effective sample is 76.

During pairwise comparison, the number of the samples in pretest and post-test has been naturally decreased.

\subsection{The Contrast between Pretest and Post-Test within Groups}

For the same group of students, they are tested in accordance with the four dimensions, namely, fluency, flexibility, originality and elaboration before and after the course learning. The researchers put the tested scores of each item into the SPSS software and give the paired samples T-test, by measuring whether there is significant differences of creativity existing before and after the training.

(1) The comparison between pretest and post-test within the chopsticks test group in Experience group

Within Experience group, for the chopsticks test, before the creative teaching of students, the mean scores of the fluency is 12.429. After using TRIZ teaching methods, the students' fluency scores have been increased to 20.163 . Similarly, the mean scores of the flexibility have been increased from 7.653 to 10.857 , and that of originality level have been increased from 10.47 to 16.43 . In summary, the overall measuring scores have been increased from 30.551 to 47.449 , and it has been increased to $55.3 \%$.

Table-1. Descriptive statistics of pretest and post-test for Experience Group chopsticks test and comparison with the differences in indicators

\begin{tabular}{|c|c|c|c|c|c|c|c|c|c|}
\hline \multicolumn{10}{|c|}{ Paired.Samples Test } \\
\hline & & \multicolumn{5}{|c|}{ Paired difference } & \multirow{3}{*}{$\mathrm{t}$} & \multirow{3}{*}{ df } & \multirow{3}{*}{$\begin{array}{l}\text { Sig. } \\
\text { (bilateral) }\end{array}$} \\
\hline & & \multirow{2}{*}{ Mean value } & \multirow{2}{*}{$\begin{array}{l}\text { Standard } \\
\text { deviation }\end{array}$} & \multirow{2}{*}{ SE Mean } & \multicolumn{2}{|c|}{\begin{tabular}{|l|} 
The difference of the \\
95\% confidence interval \\
\end{tabular}} & & & \\
\hline & & & & & Upper limit & \begin{tabular}{|l|} 
Lower \\
limit \\
\end{tabular} & & & \\
\hline Paired 1 & $\begin{array}{l}\text { Experience group post- } \\
\text { test fluency-Experience } \\
\text { group pretest fluency }\end{array}$ & $\begin{array}{l}20.163 \\
12.429\end{array}$ & $\begin{array}{l}8.7115 \\
5.2281\end{array}$ & 1.2474 & 10.2427 & 5.2267 & 6.201 & 48 & .000 \\
\hline Paired 2 & $\begin{array}{l}\text { Experience group post- } \\
\text { test flexibility- } \\
\text { Experience group } \\
\text { pretest flexibility }\end{array}$ & $\begin{array}{l}10.857 \\
7.653\end{array}$ & $\begin{array}{l}2.4238 \\
2.6891\end{array}$ & .4601 & 4.1292 & 2.2789 & 6.963 & 48 & .000 \\
\hline Paired 3 & $\begin{array}{l}\text { Experience group post- } \\
\text { test originality -Experi } \\
\text { ence group pretest origi } \\
\text { nality }\end{array}$ & $\begin{array}{l}16.43 \\
10.47\end{array}$ & $\begin{array}{l}10.930 \\
5.676\end{array}$ & 1.602 & 9.181 & 2.737 & 3.719 & 48 & .001 \\
\hline Paired 4 & $\begin{array}{l}\text { Total scores of } \\
\text { Experience group post- } \\
\text { test Total scores of } \\
\text { Experience grouppre- } \\
\text { test }\end{array}$ & $\begin{array}{l}47.449 \\
30.551\end{array}$ & $\begin{array}{l}20.9434 \\
12.9809\end{array}$ & 3.1154 & 23.1620 & 10.6339 & 5.424 & 48 & .000 \\
\hline
\end{tabular}


For the first group, TRIZ techniques' training of chopsticks pretest and post-test, the fluency, flexibility, originality and the total scores in the pretest and post-test Sig. are .000 , indicating that mean value of these groups has no significantly differences. This kind of way for creativity training can significantly influence students' thinking fluency, flexibility and originality, namely, it is effective in influencing the students' creativity. Seen from the t value, the flexibility level is highest significant, followed by fluency and originality.

However, by the standard deviation and standard error values, it can be seen that the total score and sub-scores have increased the degree of dispersion. It indicates that in the post-test of chopsticks, this group of students have the large gaps for the scores among individuals. When compared with the untrained generally flat creativity, some students accept the extent of the teaching method which is too high, resulting in a more significant upgrade of creativity, and some other changes are relatively weak.

(2) Within Experience group Human shape test, the comparison between pretest and post-test

For the human shape test of the Group1, the mean score of the students' fluency before getting the creativity teaching is 16.262. After learning TRIZ teaching methods, the scores of fluency has been upgrading to 21.4. Equally, the overall level of flexibility of the students in this group has been rising from 10.554 to 11.569 . The level of originality has been rising from 15.15 from 12.78. In summary, the overall measured score has been rising from 46.154 to 53.908, and the indicator has been increasing to $16.8 \%$. However, it is worth noting that the elaboration of the group shows a downward trend from 6.55 down to 5.78 , but the standard deviation has increased by indicating that the level of elaboration shows an overall decline after training while the differences between individuals also have increased.

In human form tests, the students from Experience group TRIZ training have the score in the fluency, the originality of the pretest and post-test and total scores for the pretest and post-test. Here, Sig is less than 0.05 , indicating that for such graphics training, students' fluency, originality and the overall level have been rising significantly after getting TRIZ techniques training. The overall score of originality and elaboration has been improved but it is not obvious.

However, by the standard deviation and standard error values, it can be seen that the total score and sub-scores has increased the degree of dispersion. It indicates that in the post-test of human shape, this group of students have the large gaps for the scores among individuals. When compared with the untrained generally flat creativity, some students accept the extent of the teaching method which is too high, resulting in a more significant upgrade of creativity, and some other changes are relatively weak.

Table-2. Descriptive statistics of pretest and post-test for Experience grouphuman shape test and comparison with the differences in indicators

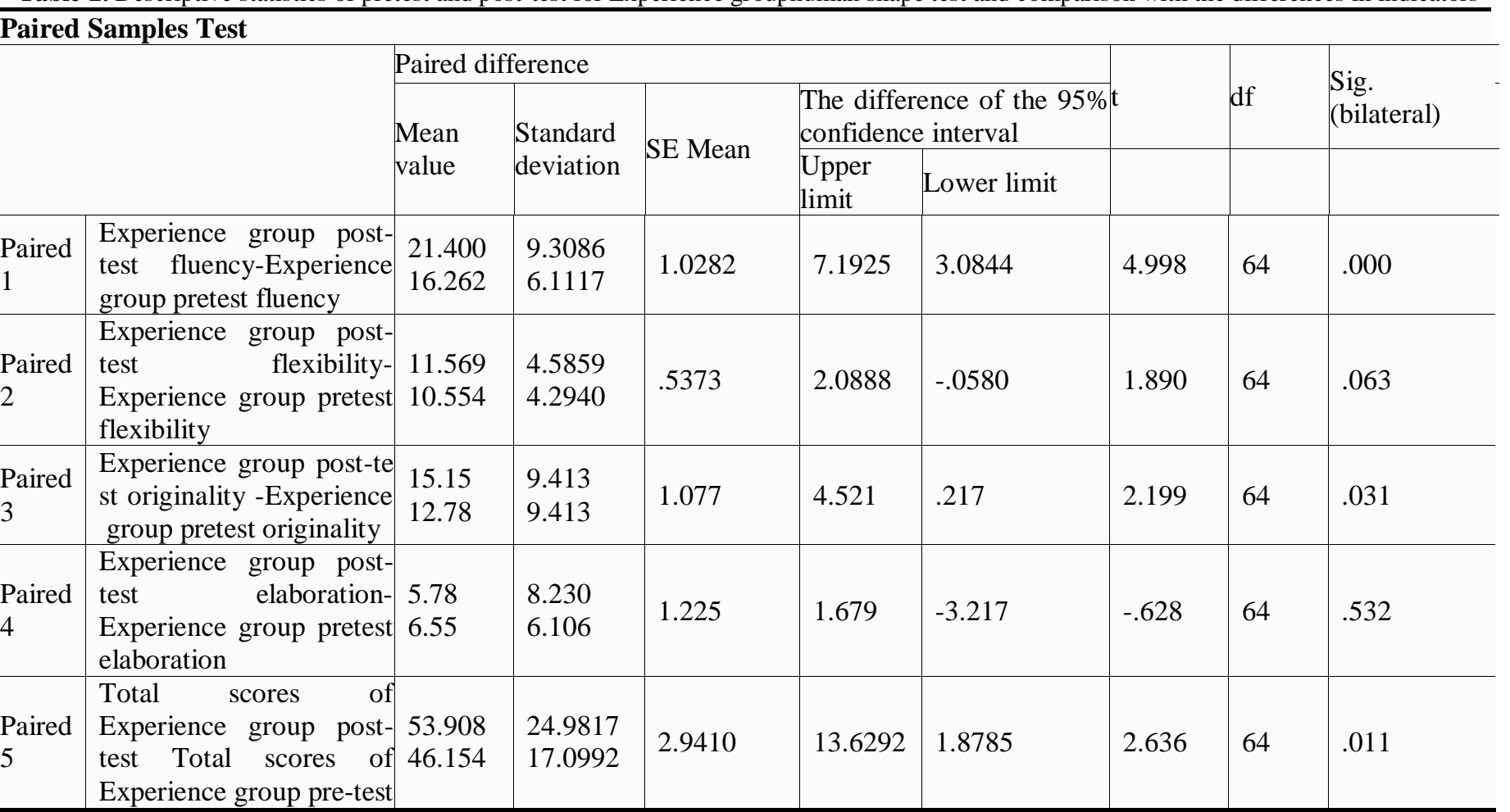

Source: Questionnaire data analysis

(3)Within Group 2 chopsticks test, the comparison between pretest and post-test

For the human shape test of the Group2, the mean score of the students' fluency before getting the creativity teaching is 11.379. After learning TRIZ teaching methods, the score of fluency has been upgrading to 21.931. The overall level of flexibility of the students in this group has been rising from 7.207 to 11.328 . The level of originality has been rising from 9.19 to 17.10. In summary, the overall measured score has been rising from 27.776 to50.362. This rising tend is significant and it accounts for $81.3 \%$.

\section{Results}

Experimental Assumption 1is accepted.

Experimental Assumption 2 that the original part of the speech test can be accepted, and the other does not accepted. 


\section{Discussions}

First, for humanities and social science students, the effectiveness of teaching TRIZ method is not clearly superior to that of the traditional teaching of creation. TRIZ method is originated from the inventive methods for solving technical problems as their advantages. For the humanities and social sciences, this method should be given further exploration.

Second, in this experiment, TRIZ teaching in cultivating students' unique nature has certain advantages. However, the data were merely obtained through the creative thinking test but they are in short of the examination of creative products, so they need to be proved further by experiments.

Third, TRIZ in the field of humanities and social sciences has not a long history in teaching and needs to strengthen the combination of the case studies of this field with the summary of innovative principles, in order to get better teaching results.

\section{References}

Boris, Z. and Z. Alla, 1993. Evaluation of organizations and social systems [J]. Journal of TRIZ, 3: 73-81.

Boris, Z., Z. Alla, K. Len and V. Svetlana, 2000. Vladimir Proseanic and sergey malkin.TRIZ beyond technology: The theory and practice of applying TRIZ to non-technicalareas. Ideation International Inc, 1: 1-58.

Csikszentmihalyi, M., 1988. Society, culture and person: A systems view of creativity. In R. J. Sternberg (Ed.), The nature of creativity. New York: Cambridge University Press. pp: 325-339.

Darrell, M., 2002. Systematic win-win problem solving in a stakeholder-conflict business environment. TRIZCON, $29:$ 55-65.

Lv, R., F. Zhang and Z. Zhang, 2010. Study on China's private express companies' strategic innovation based on TRIZ[C]//Computer Design and Applications (ICCDA) 2010 International Conference on. IEEE, 2010, 2:V2-44-V2-47.

Magdalena, G.G., J. Krzysztof and d. Szmi, 2013. Teaching for creativity: How to shape creative attitudes in teachers and in students, in mary banks gregerson. James C. Kaufman,Heather T. Snyder(Eds), Teaching creatively and teaching creativity. New York: Springer.

Marsh, D.G., 2004. Inventive principles with applications in education [J]. TRIZ Journal, 02: 33-39.

Retseptor, G., 2003. 40 inventive principles in quality management [J]. TRIZ Journal, 01: 1-25.

Retseptor, G., 2007. Inventive principles in customer satisfaction enhancement [J]. TRIZ Journal, 02: 1-40.

Saliminamin, M.H. and N. Nezafati, 2003. A new method for creating non-technologicical principles of TRIZ [J]. Triz Journal(10). Retrieved from https://triz-journal.com/new-method-creating-non-technologic-principles-triz/.

Yonghai, L. and L. Jianhua, 2009. Business model innovation of enterprises by physical contradiction Means of TRIZ[C]/Electronic Commerce and Business Intelligence. ECBI2009. International Conference on. IEEE, pp: 529-532.

Zhang, D., W. Aziguli and L. Gao, 2008. Research of methodology and theory of non-technical innovation[C]//Wireless Communications, Networking and Mobile Computing, 2008. WiCOM'08. 4th International Conference on. IEEE. pp: 1-5.

Zhang, J., K.H. Chai and K.C. Tan, 2003. 40 inventive principles with applications in service operations management [J].TRIZ Journal: 1-16.

Zhang, Y. and X. Sang, 2011. Application of separation principle in management innovation based on TRIZ[C]//Computer Science and Service System (CSSS), 2011 International Conference on. IEEE, pp: 2116-2119.

For the college students, TRIZ methods in business and science and engineering majors, such as mechanical design expertise in promotion get better results. But there are different opinions on whether the students coming from the humanities and social sciences majors carry out related training programs. Some scholars have begun to study how to apply TRIZ theory in the field of non-engineering technology, and have achieved certain results. TRIZ is no longer merely seen as "the methods for technical invention "but should be regarded as "innovative ideas". Whether this course system can be applied to the students in the field of humanities and social sciences? whether TRIZ teaching system has the effective ways in the training of students' creative ability or solving problems ? 